\title{
SUSTAINABILITY INDICATORS AND ENVIRONMENTAL SAFETY MANAGEMENT AS ILLUSTRATED WITH AN EXAMPLE OF THE POLISH ENERGY SECTOR
}

\author{
doi: $\quad 10.2478 /$ czoto-2019-0051 \\ Date of submission of the article to the Editor: 07/12/2018 \\ Date of acceptance of the article by the Editor: 23/01/2019
}

Wioletta Skrodzka ${ }^{1}$ - orcid id: 0000-0002-1930-2653

Olga Kiriliuk ${ }^{2}$ - orcid id: 0000-0001-7892-6987

${ }^{1}$ Czestochowa University of Technology, Poland, wioletta.skrodzka@wz.pcz.pl

${ }^{2}$ Omsk State Transport University, Russia

\begin{abstract}
Power engineering is one of the key areas of sustainable development. Many countries create new concepts of environmental safety management and modify their energy systems to be in line with the goals of sustainable development in the EU. Sustainable development indicators can be a tool for monitoring the set goals of environmental safety management. The aim of the article is to assess the environmental safety management of the energy sector in Poland in relation to EU as well as presenting the concept of sustainable energy development and indicators used to assess the development of energy in the following dimensions: social, economic and ecological. The indicators used to assess the sustainable development of energy in the following dimensions were compared: sustainable consumption and production, marking the production and consumption of energy; organizations and sites with eco-management and audit scheme (EMAS); registration climate change, marking GHG emissions and the share of renewable energy in gross final energy consumption; sustainable transport, marking the energy consumption of transport relative to GDP. The article will test the hypothesis that the structure of obtaining energy in Poland and the tempo of change in this respect differ from the EU average.

Keywords: energy sector, environmental safety management, sustainable energy development, energy indicators
\end{abstract}

\section{INTRODUCTION}

Depletion of global energy resources and environmental degradation are some of the basic threats to the economic development of the modern world. In these circumstances, the concepts of Environmental Management Systems (EMS) and Energy Management Systems (EnMS) are more than theoretical solutions and become practical tools for shaping the development of the economy. ISO 14001 and the Eco-Management and Audit Scheme (EMAS), for EMS, and ISO 50001 for EnMS are the most commonly implemented and certified standardized management systems. The basic assumptions of the Eco-Management and Audit Scheme (EMAS) 
were first established in the Council Regulation (EEC) 1836/93 of 23 June 1993 on the voluntary participation of industrial enterprises in the community eco-management and audit scheme (Council Regulation, 1993). The main goal of the project was to promote pro-ecological industrial activity through a unified self-assessment system and self-control of enterprises in terms of their impact on the environment. The subsequent years bought the revision of the organizational and formal-legal assumptions of EMAS. The new legal act - Regulation No. 761/2001 of the European Parliament and the Council, the so-called EMAS II, allowed participation of nonindustrial organizations in the Community Eco-Management and Audit Scheme (EMAS). And on 22 December 2009, the EMAS III regulation was published in the Official Journal of the European Union L 342 (volume 52) (Regulation (EC), 2009). In Poland the EMAS Environmental Management System is a less popular system than the system compliant with the ISO 14001 standard described below.

The international ISO 14000 series of standards were first established in 1996 and contain requirements for environmental management systems in various organizations regardless of their type, size and geographical, cultural or social conditions. On 15 November 2004 the International Organization for Standardization issued the second edition of the standard - ISO 14001: 2004, and in 2015 the revised version of ISO 14001: 2015. The basic task of the ISO 14001 standard is to support activities connected with environmental protection and the reduction and prevention of pollution. The system model for the standard is directed towards continuous improvement. The subject literature links both standards with the concept of sustainable development of the power industry. The aim of the article is to assess the environmental safety management of the energy sector in Poland in relation to EU as well as presenting the concept of sustainable energy development and indicators used to assess the development of energy in the following dimensions: social, economic and ecological. The paper attempts to assess the development of sustainable energy in Poland against the background of the European Union.

\section{METHODOLOGY OF RESERARCH}

Sustainable development of energy industry, which is a crucial element of sustainable development, is monitored with a set of various indicators in international comparisons as well as on the European level with the purpose to evaluate the goals of energy, climate and ecological policy (Iddrisu and Bhattacharyya, 2015). The measures of sustainable development enable a statistical presentation of a country from the point of view of the implementation of a new development paradigm. Their most important feature is comparability which facilitates the determination of the position of a given object, such as a country, with reference to other objects. The set of indicators of the sustainable development of the EU consists of many thematic areas, from economic, social and ecological to the institutional dimension and global partnership. They can be in the form of goals or structures which serve as reference models to be reached by sustainable development. Reaching these goals, or these positive target states in a given time is registered by the indicators of sustainable development. Sustainability related indicators have been developed since the publication of the Brundtland Report in 1987 and various efforts have been made to capture different aspects including energy sustainability dimensions (Pinter et al., 2005; Singh et al., 2012). It have to be noted that currently, the indicators published by Eurostat are presented in two ways, taking into account: the previous breakdown 
into 10 thematic areas and the new indicators system divided into 17 objectives of the Sustainable Development Strategy according The 2030 Agenda for Sustainable Development (UN, 2015). The topics are gradually moving from economic, social and environmental to institutional topics and global partnerships. These areas are then divided into subthemes that allow the presentation of operational objectives and Strategic activities. The indicators used by Central Statistical Office in Poland largely overlap with the Eurostat indicators. In order to analyze the sustainable development of energy in Poland against EU, the values of indicators leading in the following thematic areas were examined: sustainable consumption and production (electricity consumption in households per capita, organizations and sites with eco-management and audit scheme (EMAS) registration), climate change and energy (GHG emissions in $\mathrm{CO} 2$ equivalent, share of renewable energy in gross final energy consumption), organization of transport respecting the principle of sustainable development (energy consumption of transport relative to GDP). Transport is the key sector in the analysis of sustainable development. The energy consumption in transport indicator relative to GDP determines a percentage change in the final consumption of energy by transport per a GDP unit relative to 2010. A decrease in the indicator's value is a desired tendency. The indicator offers a possibility to determine the relation between energy consumption in transport and economic growth. GDP increase should not be a consequence of an increase in the consumption of energy in transport. Since 2004 the majority of the countries of EU have been reducing the final energy consumption in transport per a GDP unit. In 2015 the average for the European Union was 93,4\%. The value for Poland was $83,9 \%$. One of the main indicators for monitoring sustainable consumption and production of energy is the electric energy consumption in households per capita. It paints the picture of the consumption of electric energy by household inhabitants in time. A decrease in the indicator's value is a desired tendency. The increase of the indicator caused by lifestyle change (for example more electric appliances in a household) fosters "nonsustainable tendencies" in the consumption of energy by households which bring serious environmental impact. In 2015 the average electric energy consumption in households per capita in the UE-28 countries was 5,6GJ. The lowest value of the indicator, like in previous years, was observed for Romania 2,2 GJ and Poland 2,7 GJ. EMAS was designed to improve and promote sustainable and responsible environmental performance and resource-efficient production. The European Commission started to collect numbers of sites in addition to the number of organisations in March 2004 to give a more accurate picture of EMAS development. The number of EMAS registered organisations and sites across the European countries is highly differentiated. In 2015 the EU leaders ware: Germany, with 1991 sites, Italy, with 1771 sites and Greece, with 1292 sites. There was a sharp rise of the organisations and sites with eco-management and audit scheme (EMAS) in Poland in the last few years (increase from 33 sites in 2012 to 122 in 2015). The indicators leading in monitoring the changes in climate and energy are GHG Emissions in $\mathrm{CO} 2$ equivalent and the share of renewable energy in gross final energy consumption. The desired direction of change is the decrease in the indicator's value. Most EU countries record a drop in the total emission of greenhouse gases in relation to the base year which means they fulfill their obligation to reduce greenhouse gases emission to support sustainable development. The obligation to reduce the emission of greenhouse gases in the first period of Kyoto Protocol (2008-2012) was fulfilled by Poland with a surplus as the country's greenhouse gases emission was reduced by $29,1 \%$. Yet in order to protect the climate, further 
reductions of emission are necessary. In 2015 the emission level was 68,48\%. It is estimated that a long-term quantitative goal is to reach a $30-40 \%$ reduction of greenhouse gases emission until 2020 in relation to the base year. Another indicator in the area of tracking of climate and energy changes is the share of energy from renewable sources in gross final energy consumption. It reflects the level of energy from RES in the final energy consumption in a country. Since 2004 the countries of EU have been increasing their share of renewable energy. In 2015 the average share of energy from renewable sources in gross final consumption the UE-28 countries was $26,7 \%$. In 2015 , Poland with the share of energy from renewable sources in gross final consumption on the level of $11,8 \%$ took a position far behind Sweden (53,9\%), Finland $(39,2 \%)$, Austria $(33,0 \%)$ and Denmark $(30,8 \%)$ where the values of the indicator were highest. Since 2008 in Poland the share of renewable energy in gross final consumption has been on a constant but slight increase. It went from $6,9 \%$ to $11,3 \%$ in the years $2004-2007$, and up to $13,6 \%$ in 2016. The observed increase of energy from renewable sources is also reflected in the growing diversification of these sources. The share of RES in gross final consumption often differs from the share in primary production.

In order to analyze the intensity of changes in the sector structure of energy production, we use a measure determining structural changes proposed by Rutkowski (Rutkowski, 1981). It is a variability coefficient of the indexes of the analyzed aggregation's growth, which at the same time measures the irregularity of the increase of the aggregate's components (Skrodzka, 2016).

$$
V_{t, t+\tau}^{i}=\left[\sum_{j=1}^{k} f_{j, t+\tau}^{i}\left(\frac{f_{j, t+\tau}^{i}}{f_{j, t}^{i}}-1\right)^{2}\right]^{\frac{1}{2}}
$$

Where:

$f_{j, t+\tau}^{i}, f_{j, t}^{i}$ - the structure index in moments $\mathrm{t}$ and $\mathrm{t}+\mathrm{T} ; \mathrm{j}=1,2, \ldots \mathrm{k}$ - components of the structure aggregate; $\mathrm{i}-$ object number.

$V_{t, t+\tau}^{i}=0$ indicates the lack of change in the structure between periods. The higher the value of the measure, the more significant the structural changes.

In the next stage of the analysis we will compare the sector structure of the primary energy production in Poland with the sector structure in the whole European Union. Object similarity measure are used in analysis of this type (Malina, 2004). The measure is based on the value of the cosine of the $\alpha$ angle measured between the $U_{t 1} i U_{t 2}$ vectors characterizing the state of the structure in respective periods $t 1$ and $t 2$.

$$
\cos \alpha=\frac{\sum_{j=1}^{k} f_{j, t}^{1} \cdot f_{j, t}^{2}}{\sqrt{\sum_{j=1}^{k}\left(f_{j, t}^{1}\right)^{2} \cdot \sum_{j=1}^{k}\left(f_{j, t}^{2}\right)^{2}}}
$$

Where:

$f_{j, t}^{1}, f_{j, t^{-}}^{2}$ components of the structure indexes vector respectively for Poland and the European Union.

The values of the measure are normalized, but to interpret the structures similarity assessment level, we consider the angle represented by the calculated cosine. A big a spread between the $U_{t 1}$ and $U_{t 2}$ vectors means significant structure changes in 
period $t 2$ in comparison to the structure in period $t 1$. A small spread of the angle indicates slight structure changes in the discussed periods. In an exceptional case, when the compared structures are identical, the angle between the structure vectors is 0 . When the cosine value tends toward 0 , which means the angle tends toward $90^{\circ}$, the vectors represent increasingly different structures. Arbitrary ranges determining small, medium or high structure similarity were set. The values of the cosine function for the division of a $90^{\circ}$ angle into 3 equal parts were assumed as the ends of the ranges: $[0,1 / 2]$ - big difference in structures; $[1 / 2, \sqrt{3} / 2]$ - moderate diversification of the structures; $[\sqrt{3} / 2,1]$ - high similarity. The function is not linear with respect to the angle, so we need to take caution expressing the size of structure changes in percentage.

\section{RESULTS}

The analysis of the changes in the structure of primary energy production in Poland and EU-28 is based on data from the Eurostat energy balance 2010 and 2016 on a yearly basis. Analyzing the volume of output of the primary energy in the EU in the period 2004-2016 we observe a negative trend for the majority of energy sources, except for renewables (Table 1).

Table 1

Primary energy production, Share of each fuel to total production in EU-28 and in Poland, 2010-2016 (Mtoe).

\begin{tabular}{|c|c|c|c|c|c|c|c|}
\hline & $\begin{array}{c}\text { Total } \\
\text { production } \\
\text { (Mtoe) }\end{array}$ & $\begin{array}{l}\text { Solid } \\
\text { fuels }\end{array}$ & $\begin{array}{c}\text { Oil } \\
\text { (total) }\end{array}$ & $\begin{array}{c}\text { Natural } \\
\text { gas }\end{array}$ & $\begin{array}{l}\text { Nuclear } \\
\text { energy }\end{array}$ & $\begin{array}{c}\text { Renewable } \\
\text { energy }\end{array}$ & $\begin{array}{c}\text { Wastes } \\
\text { (non } \\
\text { ren.) }\end{array}$ \\
\hline \multicolumn{8}{|l|}{2010} \\
\hline EU-28 & 831.6 & 164.0 & 97.1 & 159.8 & 236.6 & 163.0 & 11.1 \\
\hline PL & 66.9 & 55.1 & 0.7 & 3.6 & 0.0 & 6.9 & 0.6 \\
\hline \multicolumn{8}{|l|}{2011} \\
\hline EU-28 & 802.9 & 166.6 & 84.8 & 141.7 & 234.0 & 162.2 & 13.6 \\
\hline PL & 67.9 & 55.3 & 0.7 & 3.9 & 0.0 & 7.4 & 0.6 \\
\hline \multicolumn{8}{|l|}{2012} \\
\hline EU-28 & 794.6 & 166.1 & 76.7 & 133.2 & 227.7 & 177.4 & 13.6 \\
\hline PL & 71.1 & 57.5 & 0.7 & 3.8 & 0.0 & 8.5 & 0.6 \\
\hline \multicolumn{8}{|l|}{2013} \\
\hline EU-28 & 790.3 & 155.8 & 71.6 & 131.8 & 226.3 & 192.8 & 12.0 \\
\hline PL & 70.5 & 56.8 & 0.9 & 3.8 & 0.0 & 8.5 & 0.5 \\
\hline \multicolumn{8}{|l|}{2014} \\
\hline EU-28 & 771.7 & 149.3 & 70.0 & 118.0 & 226.1 & 195.8 & 12.4 \\
\hline PL & 66.8 & 53.6 & 0.9 & 3.7 & 0.0 & 8.1 & 0.5 \\
\hline \multicolumn{8}{|l|}{2015} \\
\hline EU-28 & 766.6 & 144.9 & 75.1 & 107.3 & 221.5 & 204.7 & 13.0 \\
\hline PL & 67.3 & 53.6 & 0.9 & 3.7 & 0.0 & 8.6 & 0.5 \\
\hline \multicolumn{8}{|l|}{2016} \\
\hline EU-28 & 755.4 & 132.2 & 74.0 & 107.3 & 216.8 & 210.8 & 14.3 \\
\hline PL & 66.4 & 52.1 & 1.0 & 3.5 & 0.0 & 9.0 & 0.8 \\
\hline
\end{tabular}

Source: Eurostat [online]; [cit.2018-10-17], Available:data codes: ten00076, ten00080 and ten00081

Primary production of energy in the EU-28 in 2016 dropped by $1.5 \%$ compared to 2015.The biggest decrease was observed in the production of fossil fuels gas (8\%), followed by the production of nuclear energy $(2.1 \%)$ and petroleumderived products (1.5\%). The production of energy from renewable sources, on the other hand, increased by 3\%. The most popular sources of renewable energy in EU-28 in 2016 
were: biomass combustion (63.8\%), hydroelectric plants (14.2\%), wind power plants $(12.3 \%)$, solar energy (6.3\%) and geothermal energy (3.2\%). Gross inland energy consumption in the EU-28 in 2016 was 1640.6 Mtoe, and the final energy consumption was on the level of 1107.8 Mtoe (Eurostat, 2018). As for the structure of gross inland energy consumption in 2016, petroleum products held the biggest share $(34.6 \%)$, followed by gas $(23.3 \%)$ and solid fossil fuels $(14.7 \%)$, which means that $71.5 \%$ of all energy in the EU-28 was produced from fossil sources (coal, crude oil, natural gas). The share of nuclear heat and renewable energies accounted for $13.2 \%$ each. Gross inland energy consumption in Poland in 2016 was 99.9 Mtoe, and the final energy consumption was on the level of 66.7Mtoe (Eurostat, 2018). Production in Poland in the analyzed period is based on fossil fuels which in 2016 accounted for $78.4 \%$ of the production. There seems, however, to be an upward trend in the percentage of renewable energy. In 2016 it was on the level of $13.6 \%$, followed by gas $(5.3 \%)$, and petroleum products $(1.5 \%)$. In Poland there are no nuclear power plants. Angle measure was used to assess the similarity of the primary energy production structure in Poland and in EU-28. The results are shown in table 2.

Table 2

The Values of the Structure Similarity Measures

\begin{tabular}{|c|c|c|c|c|c|c|c|}
\hline Years & $\mathbf{2 0 1 0}$ & $\mathbf{2 0 1 1}$ & $\mathbf{2 0 1 2}$ & $\mathbf{2 0 1 3}$ & $\mathbf{2 0 1 4}$ & $\mathbf{2 0 1 5}$ & $\mathbf{2 0 1 6}$ \\
\hline cos $\alpha$ & 0,510956 & 0,534324 & 0,571103 & 0,522292 & 0,513696 & 0,508244 & 0,461249 \\
\hline
\end{tabular}

Source: Own calculations

The analysis showed a significant difference between the structures of primary energy production in Poland and in EU-28 in 2016, the angle between the vectors is $62.5^{\circ}$. In the other years it hovers around $58^{\circ}$, which suggests a moderate similarity of the structures. In the next step we determined the intensity of the structural changes in the analyzed period using the formula (1). The values of the structural change intensity measure are presented in table 3.

Table 3

The Dynamics of the Structural Change in Primary Energy Production in Poland and in EU-28 in the Period 2011-2014

\begin{tabular}{|c|c|c|}
\hline \multirow{2}{*}{ Years } & Change intensity measure in comparison to the previous year \\
\cline { 2 - 3 } & EU-28 & Poland \\
\hline $\mathbf{2 0 1 1}$ & 0.065499 & 0,026761 \\
\hline $\mathbf{2 0 1 2}$ & 0.060816 & 0.038192 \\
\hline $\mathbf{2 0 1 3}$ & 0.057232 & 0.036444 \\
\hline $\mathbf{2 0 1 4}$ & 0.041878 & 0.011127 \\
\hline $\mathbf{2 0 1 5}$ & 0,050549 & 0,020459 \\
\hline $\mathbf{2 0 1 6}$ & 0,042761 & 0,075215 \\
\hline $\mathbf{2 0 1 6 : 2 0 1 0}$ & 0,260484 & 0,139589 \\
\hline
\end{tabular}

Source: Own calculations

Both measures have low, similar range values, which means that the intensity of the change tempo in the analyzed structures is also low. But measures for EU-28 are higher which suggests a greater intensity of the changes in the whole European Union than in Poland. The strongest changes in the sector structure of production in EU-28 took place in 2011, and in Poland in 2016. The last line of table 6 shows the value of the measure for the first and the last year 2016:2010. Regardless of the change path 
and concentrating on the two boundary years, we can say that the intensity of changes in 2016 compared to 2010 was higher in the whole EU than in Poland

\section{DISCUSSION}

The main dilemmas related to the conceptualisation of the term of sustainable development include, inter alia, doubts raised by some authors (Kajikawa et al., 2014; Sauve et al., 2016; Garces-Averbe and Canon-de-Francia, 2017) regarding the possibility of meeting, in practice, the basic assumption of the equivalence of all domains (economic, social and environmental) of sustainable development. New Agenda for Sustainable Development 2030 covers 17 goals, among which goal 7 is key - to secure access to low-cost, sustainable energy to everyone. The subject literature gives a few definitions of the sustainable development of energy (Patterson, 2009; Lemaire, 2004; Tester et all.,2005). Long-term accessibility, as the central interest of the concept of sustainable development, should be offered in accordance with the environmental protection requirements. The social aspect is not as emphasized as environmental matters, but is also present in the definitions of sustainable energy (Tester et all.,2005). The policy of sustainable energy in three dimensions: ecological, economic and socio-cultural is also described by $\mathrm{H}$. Rogall (Rogall, 2009) and G. P. Hammond i C.I. Jones (Hammond and Jones, 2011). According to the quoted authors, in the framework of the environmental pillar the effects of the application of a given technology should be subject to environmental impact assessment. The subject literature highlights the importance of the entire sustainable energy system which meets the requirements of the concept of sustainable development. It also emphasizes that efficient energy management is just as significant as its efficient production (Mitchel, 2010;).

\section{CONCLUSION}

The concept of sustainable development has since the beginning enjoyed considerable interest among researchers from various fields of science. The paper presents the concept of sustainable development of energy industry as a process of sustainable, secure and effective supply of energy which is a significant element of sustainable development. It offers a comparison of leading indicators of the development of sustainable energy in the area of sustainable consumption and production, climate and energy change and sustainable transport. One of the principal indicators for monitoring sustainable consumption and production of electric energy is the consumption of energy in households per capita. In 2015 the average electric energy consumption in households per capita in the UE-28 countries was 5,6GJ. The lowest value of the indicator, like in previous years, was observed for Romania 2,2 GJ and Poland 2,7 GJ. In the area of monitoring climate and energy change in 2015 Poland saw a decrease in the total emission of greenhouse gases compared to the emission in the base year which means it realized their obligations to reduce greenhouse gases to support sustainable development. In Poland, as in other the UE-28 countries, the share of energy from renewable sources in gross final energy consumption is constantly growing. The share of RES in gross final consumption often differs from the share in primary production. The study also analyzes the structure of primary energy production in sectors and its dynamics in Poland, and compares it to the structure in the UE-28 in the years 2010 - 2016. The conclusion drawn is that the discussed structures differ significantly. The Polish power industry is different from the 
production structure in the European Union. In the analyzed period we observed changes in this structure but they were more intense in the whole EU-28 than in Poland. The indicators of the sustainable development of energy are the background and a basis of information on a country's energy situation. They show socio-economic context which determines the progress in pursuing and reaching the sustainable development of energy industry which is an integral part of the European Union Strategy for Sustainable Development.

\section{REFERENCES}

Garces-Averbe, C., Canon-de-Francia, J., 2017, The relevance of complementarities in the study of the economic consequences of environmental proactivity: analysis of the moderating effect of innovation efforts. Ecol. Econ. 142, 21-30

Hammond G.P., Jones C. I., 2011, Sustainability criteria for energy resources and technologies, In Handbook of Sustainable Energy, I. Galarraga, M. GonzalesEguino, and A. Marakandya, Eds. Cheltenham: Edward Elgar.

Iddrisu I., Bhattacharyya S., 2015, Sustainable Energy Development Index: A multidimensional indicator for measuring sustainable energy development, Renewable and Sustainable Energy Reviews, Vol. 50, 513-530

Kajikawa, Y., Tacoa, F., Yamaguchi, K., 2014. Sustainability science: the changing landscape of sustainability research. Sustain. Sci. 9 (4), 431-438.

Kapustka, K., Ziegmann G. and Dorota Klimecka-Tatar, D., 2018, Problems in waste management in the aspect of the secondary use of plastics from WEEE. MATEC Web of Conferences 183,

01011, DOI: https://doi.org/10.1051/matecconf/201818301011

Lemaire X., 2004,Glossary of Terms in Sustainable Energy Regulation, Renewable Energy and Efficiency Partnership, Centre for Management under Regulation, Warwick Business School, University of Warwick.,

Malina A., 2004, Multidimensional analysis of the spatial diversification of the Polish structure of the economy by voivodeships. Wydawnictwo Akademii Ekonomicznej w Krakowie, Kraków

Mitchel C., 2010, The Political Economy of Sustainable Energy, Palgrave Macmillan UK, Basingstoke, p. 9.

Patterson W., 2009, Keeping the Lights On. Towards Sustainable Electricity, Earthscan, London, p. 14.

Rogall H., 2009, Nachhaltige Ökonomie. Ökonomische Theorie und Praxis einer Nachhaltigen Entwicklung. Metropolis Verlag.

Rutkowski J., 1981 Similarity of structures and structural changes - questions of quantification. Wiadomości Statystyczne, vol. 8.

Sauve, S., Bernard, S., Sloan, P., 2016. Environmental sciences, sustainable development and circular economy: Alternative concepts for trans-disciplinary research. Environ. Dev. 17, 48-56

Singh R. K.,Murty H. R.,Gupta S. K., Dikshit A. K., 2012, An overview of sustainability assessment methodologies. Ecol Indic;15; 281-99.

Skrodzka W., 2016, Analysis of the Structure of Primary Energy Production in Poland against the European Union In3rd International Conference on European Integration, Ostrava: VŠB-TU Ostrava, Faculty of Economics, 867-874.

Tester J.W., Drake E.M., Golay M.W., Discoll M.J., Peters W.A., 2005, Sustainable Energy, Choosing Among Options, The MIT Press, London 